International Journal of Engineering \& Technology, 7 (3.17) (2018) 123-128
International Journal of Engineering \& Technology
SPC
Website: www.sciencepubco.com/index.php/IJET
Research paper

\title{
Study on the Modification Effect of Side Pot And Diffuser to the Aerodynamics of the F1 IN SCHOOLS Car
}

\author{
Mohamad Faiz Paturrahman, Mohd Radzi Abu Mansor*, Zambri Harun and Mohd Anas Mohd Sabri \\ Department of Mechanical \& Materials Engineering \\ Faculty of Engineering \& Built Environment \\ Universiti Kebangsaan Malaysia, 43600 UKM Bangi, Malaysia \\ *Corresponding author Email: radzi@ukm.edu.my
}

\begin{abstract}
The F1 IN SCHOOLS competition was established in 2004 to develop students' interest towards science, technology, engineering and mathematics (STEM) in the secondary school phase. The application of aerodynamics is one of the important aspects studied during this phase. There are two factors that must be considered in the analysis affecting the aerodynamic performance of the car, namely the maximum velocity of the drag coefficient and the downforce coefficient. The F1 IN SCHOOLS car velocity is mainly related to its aerodynamic design and features. The objective of this paper is to study the effect of different side pot and diffuser designs that are capable of producing a low drag coefficient while maintaining a sufficient downforce coefficient. The simulation study was conducted using CFD STAR CCM+ software. The results will help to produce a miniature car that will meet two important criteria of low drag coefficient and sufficient downforce coefficient.
\end{abstract}

Keywords: F1 IN SCHOOLS; Aerodynamics; Drag Force; Downforce, CFD; Side Pot, Diffuser.

\section{Introduction}

The F1 IN SCHOOLS initiative is a global competition aiming to change student's perspectives towards science, technology, engineering and mathematics (STEM) subjects. Since 2004, the F1 IN SCHOOLS initiative has been introduced to many countries globally, receiving positive responses. Indeed, this competition exposes the participants to challenging and interesting concepts in the engineering environment. Furthermore, it requires students to study and apply these concepts such as the concept of aerodynamics, fluid dynamics, mechanical design and physics to create a quality miniature car that can perform well regarding speed and stability [1]. The maximum speed of the car is considered to be the most important parameter and therefore must be the participant's primary focus during the manufacturing process. The maximum speed of the car model is mainly affected by its aerodynamics which is the drag force and downforce.

Notably, the downforce is one of the more important aspects in real Formula $1(\mathrm{~F} 1)$ racing compared to the reduction of the drag of the car, since an F1 car is involved in numerous lap cornering. Furthermore, in real F1 racing, the downforce is an important aspect to ensure that the tires always have a strong grip to the track's surface given the power of the car. Therefore, sufficient downward force must be achieved to control the car while cornering. The situation is different when compared with the F1 IN SCHOOLS car because the car model in this case, needs to be designed with a reduction in drag compared to the downforce. Notwithstanding, this is due to the F1 IN SCHOOLS car powered by carbon dioxide gas released from the $\mathrm{CO} 2$ canister attached at the rear end of the car body.
On the other hand, drag force will also be generated in the opposite direction from the direction of movement of the car, thereby affecting the performance of the F1 IN SCHOOLS car in terms of speed. Therefore, the design of the car is more concerned with aspects to reduce the drag force as compared to the downforce. However, a sufficient amount of downforce is required in order to maintain the stability of the car. The F1 IN SCHOOLS car comes with tether line guides which are attached to a wire along the 20metre track to control the straight movement of the miniature car. Also, a sufficient amount of downforce is required to prevent the wire attached underneath the car from being overly strained that in-turn, will affect the speed of the car during a race.

Drag force may be defined as the force that prevents a solid body to accelerate as it travels through fluid flow [2] which will in effect, reduce the speed of the car during the race. The drag force is divided into two categories; pressure and skin friction drag. Pressure drag depends on the shape of an object moving through the fluid, while skin friction depends on the friction between moving surfaces with a viscous fluid [3]. The main factors that contribute to the drag force are notably, the difference between the pressure in the front and rear parts of the car, and the flow separation zone that occurs at the rear of the car. Air molecules will tend to stagnate at the front of the car and will cause the stagnation pressure to increase. Accordingly, the stagnation pressure produced will cause the drag force to decrease due to the force produced, acting in the opposite direction of the car's motion.

The flow separation zone that occurs at the rear of the car will additionally cause the drag force to increase as the air molecules cannot fill the zone that will inevitably create a low-pressure zone. Thus, this will create a pulling force on the car's body [4]. From 
this study, the drag coefficient of the car will be obtained and used to calculate the drag force by applying Eq. (1) [5].

$C_{D}=F_{D} / 1 / 2 \rho V^{2} A$

Where $F_{D}$ is the drag force, $\rho$ is the density of air, $V$ is the velocity of air and $A$ is the frontal area of the object.

Importantly, downforce is a reaction force that acts on the surface of the car. The opposite force of downforce is lift force. Furthermore, the main purpose of downforce is to ensure that the car's wheels are always in contact with the track's surface in order to prevent the car from veering off-track [6]. So, it is extremely important for the car during the race as it helps to maintain the stability of the car and to ensure that the car is always in contact with the surface of the track. As we all know, for more than four decades, downforce in relation to motorsport has become one of the key parameters for determining the performance of the vehicle [7] Further, the downforce acting on the car body can be related to the downforce coefficient using Equation (2) as given below [5]:

$C_{D N}=F_{D N} / 1 / 2 \rho V^{2} A$

Where $C_{D N}$ is the downforce coefficient, and $F_{D N}$ is the downforce, $\rho$ is the density of air, $V$ is the velocity of air, and $A$ is the frontal area of the object.

To minimise the drag force, air flow separation must be reduced. Modifying the car's body and installing a diffuser at the bottom rear part of the car model is one of the solutions. In this case, the air can be directed to flow into the flow separation zone and decrease the drag force. With the addition of a diffuser at the bottom rear part of the car with the optimum angle, the air flow at the bottom of the car will be directed into a low-pressure zone at the rear of the car. The speed of the car will increase as the lowpressure zone is reduced. Moreover, with the addition of a vertical fence on the diffuser, it will also contribute to the reduction of drag. The design of the diffusers may also influence the drag force, downforce and downforce distribution of the car. In a real F1 car, the diffuser has a positive impact where it increases up to $40 \%$ of the total downforce to the vehicle [8].

Also, the diffuser angle relative to the ground plays a very important role in the effectiveness of the installation. For instance, if the diffuser is built too steep, it will cause a separation of the air flow underneath the car and increase both turbulence and drag. On the other hand, if it is built too shallow, it will reduce the ability of the diffuser to create low pressure at the bottom of the F1 car. Notably, drag provides for more complex behaviour than downforce. Trends have been shown to decrease the drag caused by underbody upsweep at high altitude speeds of the car and will increase commensurate with a diffuser with low car height. Furthermore, the diffuser angle will also provide a huge influence on the downforce of the car [9].

Another approach that will contribute to decreasing the drag force is the design of the side pot. Air flow passing over the front of the car will inevitably flow to the side pot of the car. The design of the side pot can launch more air flow that is being interrupted by the front wheels of the car. Air passing through the smooth surface of the side pot in turn will help to reduce the drag force of the car as it acts to block the flow of air out from the tires hitting the rear of the car. When the flow of air flow is directed to the tires, it will create turbulence that will interfere with the car's air flow dynamics [10]. For the F1 IN SCHOOLS car, this will further stabilise the entire body of the car as the race progresses.

Also, a factor that significantly affects the aerodynamics of the car is the design of the side pot. The application of the inverted wing shape design to the side pot will increase downforce. According to Bernoulli's principle, air that passes at the top of the wing must flow over a longer distance, and therefore it must flow faster than the air at the bottom of the wing [11]. The higher the velocity of the air flow, the shorter the distance of the air passing over the wings, as in a similar situation at the bottom of the wing. As a result, the air above the wing has a lower pressure than the air below the wing. So, this will create a difference in lift on the wing. Moreover, this design can be applied in the F1 IN SCHOOLS car to increase the downforce on the car.

This study will principally focus on the design of the side pot and diffuser of the car to obtain a low drag coefficient and sufficient downforce coefficient acting on the F1 IN SCHOOLS car. Furthermore, some modification of the under-tray design of the car which is located below the body of the car will be undertaken to ensure smooth air flow. This study will use STAR CCM+ software to perform the simulation on the F1 IN SCHOOLS car. The simulation result will be used to obtain and compare the drag and downforce coefficient of the car.

\section{Methodology}

Figure 1 illustrates the overall flow chart for this study.

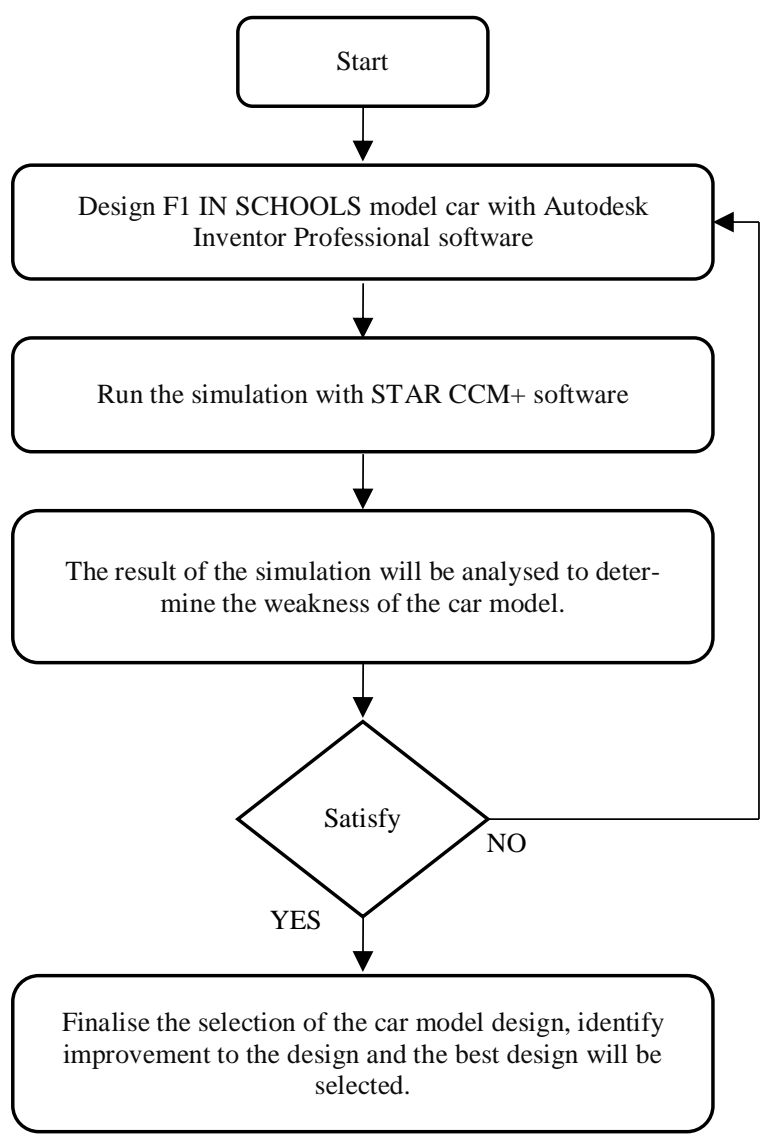

Fig. 1: Methodology flowchart

The base car, which is car model design 1, is adapted from the best car design based on [12]. The focus of this study is to design the new side pot and diffuser and to run the simulation in STAR $\mathrm{CCM}+$. The comparison of the results of the frag and downforce coefficient will be used as the primary considerations for all designs. Figure 2 illustrates 5 different designs of the F1 IN SCHOOLS car model used in this study.

As shown in Figure 2, the modifications for designs 1 to 3 are at the side pot, while for design 4 , the modification occurs at the side pot and also under the tray body. For car model design 5, the design is based on the design of car model 4 , but with modification at the diffuser and the change of angle of the underbody slice 
which is changed from $5^{\circ}$ to $13.5^{\circ}$. The thickness of the diffuser is also changed from $2 \mathrm{~mm}$ to $1 \mathrm{~mm}$ for design 5 .
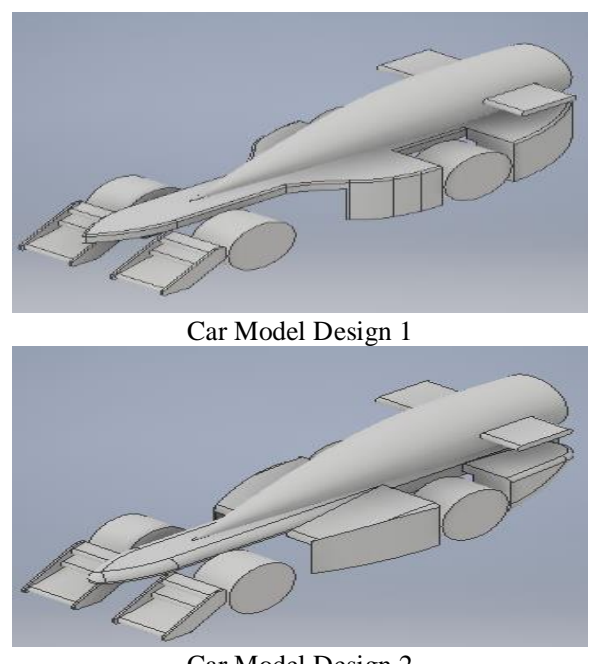

Car Model Design 2

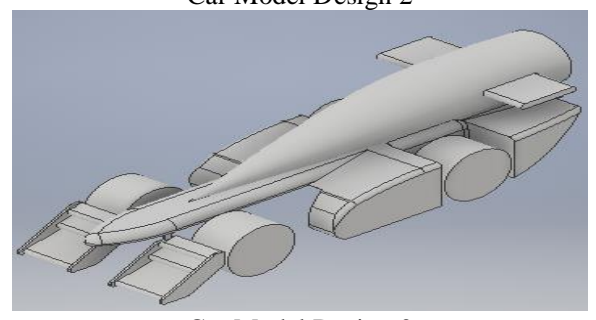

Car Model Design 3

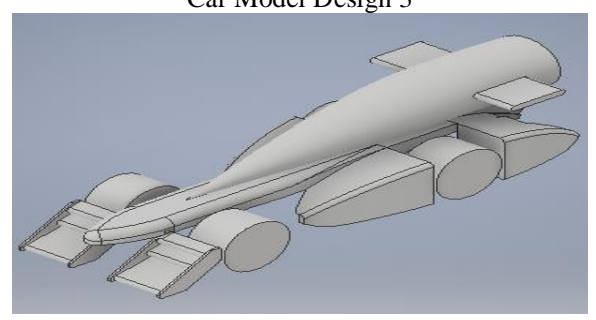

Car Model Design 4 \& 5
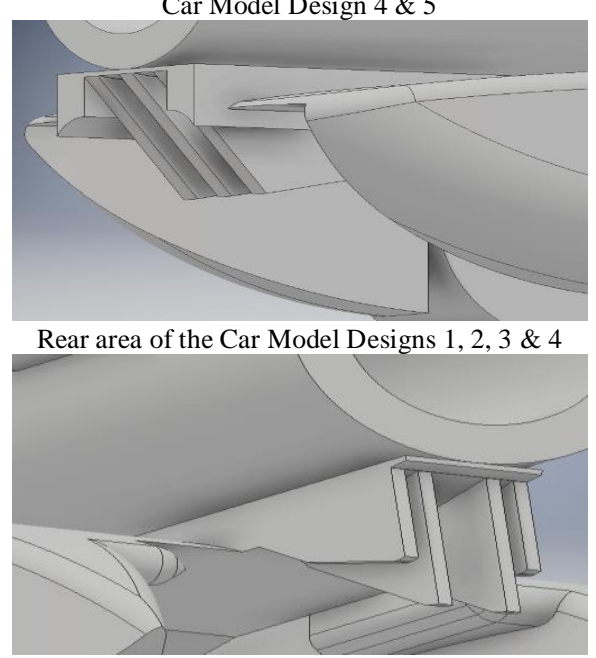

Rear area of Car Model design 5

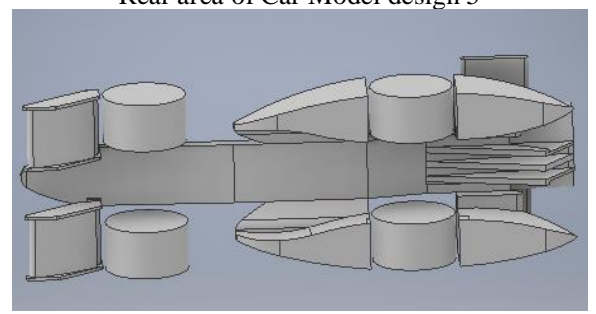

Design of the under-tray for Car Model designs $4 \& 5$

Fig. 2: Design of different Car Models.

\section{Star Ccm+ Simulation}

In this study, STAR CCM+ is used as the simulation software to execute the model to determine the value of drag and the downforce coefficient. Furthermore, the simulation aims to study the behaviour of the external airflow passing through the car model. The airflow can be observed using the velocity streamline of the airflow inside the simulation. The characteristics such as the physic model and mesh model in this simulation will also be discussed. The selection of the physic model and mesh model should be carefully decided as it will affect the results of the simulation. All the stages of executing the simulation work are displayed in Figure 3.

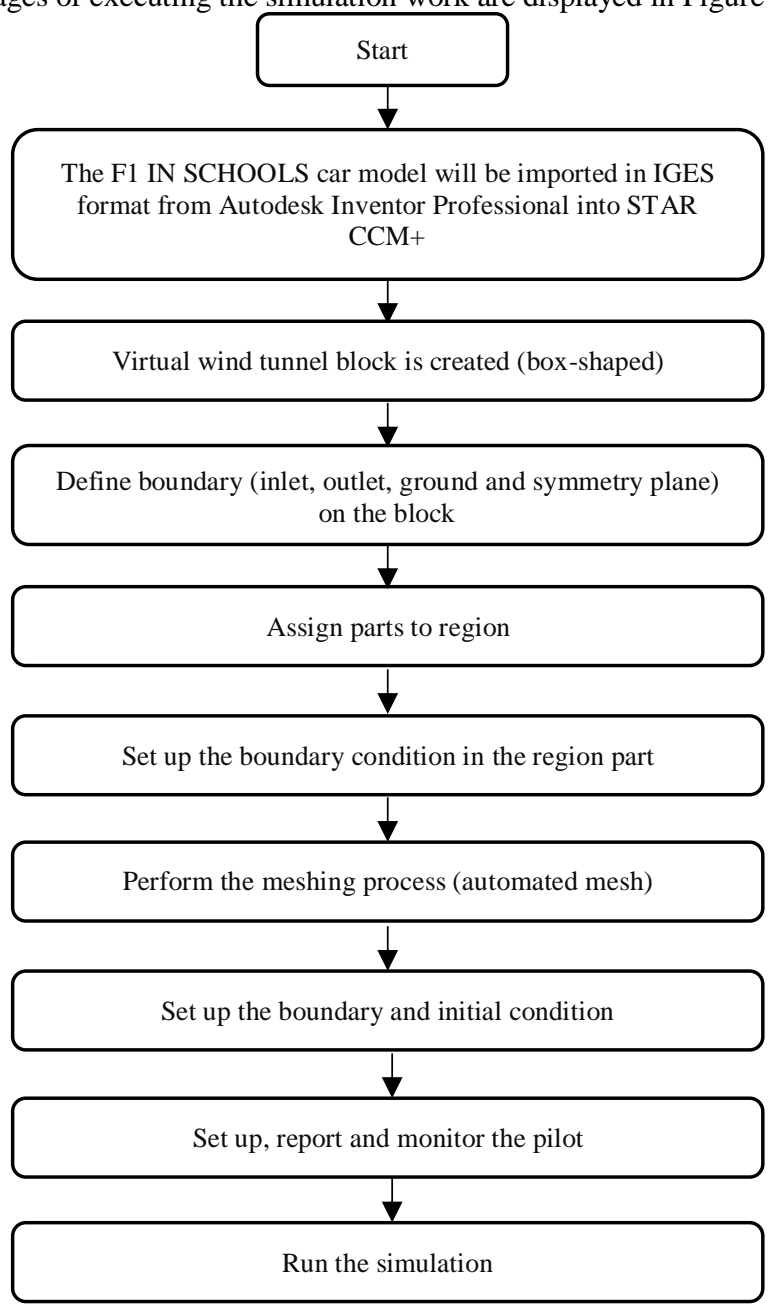

Fig. 3: STAR CCM+ simulation flowchart

The dimension of the virtual wind tunnel block is ' $1.08 \mathrm{~m} \times 0.10$ $\mathrm{m} \times 0.15 \mathrm{~m}$ ' in length, width and height respectively. The car model is placed at 1 car-length (CL) from the inlet of the block and 7 car-lengths from the pressure outlet. Figure 4 shows the meshed diagram of the car inside the block.

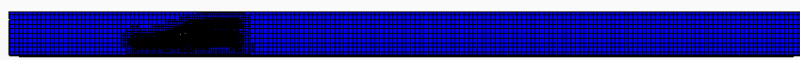

Fig. 4: Meshed diagram of the car and the wind tunnel block.

To reduce the complexity of the simulation, the car model is only half of the actual model used and is attached to the virtual tunnel block. For the stage of selecting the physic and meshing models, model selection is important since it is related to the method of computation during the simulation. The reasons for selecting each model in the simulation are shown in Table 1. 
Table 1: Reasons for selecting the physic and meshing models.

\begin{tabular}{|c|c|c|}
\hline Continuum & Type & Description \\
\hline \multirow[t]{3}{*}{$\begin{array}{l}\text { Meshing } \\
\text { model }\end{array}$} & $\begin{array}{l}\text { Surface } \\
\text { remesher }\end{array}$ & $\begin{array}{l}\text { - Optimised surface mesh generation } \\
\text { volume. } \\
\text { - To help generate sub-surface. } \\
\text { - Improve the quality of the surface of the } \\
\text { model. }\end{array}$ \\
\hline & Trimmer & $\begin{array}{l}\text { - It is particularly suitable for external } \\
\text { aerodynamic flow modelling. This is } \\
\text { because it can smooth the mesh cells at } \\
\text { the wake flow. } \\
\text { - Grid resulting in the generation of high- } \\
\text { quality networking. }\end{array}$ \\
\hline & $\begin{array}{c}\text { Prism layer } \\
\text { mesher }\end{array}$ & $\begin{array}{l}\text { - Used by the number of impressions and } \\
\text { to create prismatic cells adjacent to the } \\
\text { wall surface to produce a precise bound- } \\
\text { ary layer. } \\
\text { - Improved accuracy of the flow solution. }\end{array}$ \\
\hline \multirow[t]{3}{*}{$\begin{array}{l}\text { Physic } \\
\text { model }\end{array}$} & $\begin{array}{c}\text { K-omega } \\
\text { model }\end{array}$ & $\begin{array}{l}\text { - Improve the performance of the bounda- } \\
\text { ry layer. } \\
\text { - Suitable for use in all boundary layers } \\
\text { and in a region dominated by viscosity. }\end{array}$ \\
\hline & $\begin{array}{l}\text { Segregated } \\
\text { flow }\end{array}$ & $\begin{array}{l}\text { - This flow is used in accordance with the } \\
\text { compressible flow and incompressible } \\
\text { flow (low Mach number). } \\
\text { - Suitability for use in this type of fixed } \\
\text { density model. } \\
\text { - Requires low memory. }\end{array}$ \\
\hline & $\begin{array}{l}\text { Cell quality } \\
\text { remediation }\end{array}$ & $\begin{array}{l}\text { - Used for a low-quality mesh cell to } \\
\text { prevent the accuracy of the solution. } \\
\text { - Contributes to the solution flow at low } \\
\text { cell networks. }\end{array}$ \\
\hline
\end{tabular}

Following the selection of the physic and meshing model, the surface mesh and volume mesh are then generated. Figure 5 illustrates the model of the car after the meshing process is completed. The boundary condition and air properties are next defined before running the simulation. The boundary conditions at the inlet, outlet and car body must also be defined before running the simulation. All boundary conditions and their respective values are tabulated as shown in Table 2.

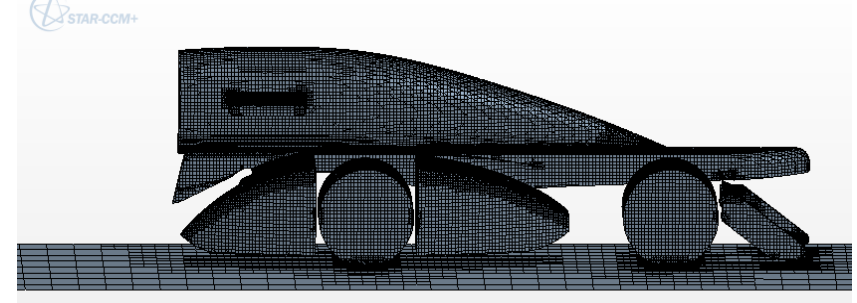

Fig. 5: Car model after meshing is completed.

Table 2: Reason for selecting the physic and meshing models.

\begin{tabular}{|c|c|c|}
\hline Continuum & Type & Description \\
\hline \multirow{3}{*}{ Air properties } & Density $\left(\mathrm{kg} / \mathrm{m}^{3}\right)$ & 1.177 \\
\cline { 2 - 3 } & Dynamic viscosity $(\mathrm{Pa}-\mathrm{s})$ & $1.846 \times 10^{-5}$ \\
\cline { 2 - 3 } & Temperature $(\mathrm{K})$ & 300 \\
\hline \multirow{7}{*}{ Velocity inlet } & Velocity $(\mathrm{m} / \mathrm{s})$ & 22.2222 \\
\cline { 2 - 3 } & Gauge pressure $(\mathrm{Pa})$ & 0 \\
\cline { 2 - 3 } & Turbulence viscosity ratio & 100.0 \\
\cline { 2 - 3 } & Turbulence intensity & 0.03 \\
\hline \multirow{2}{*}{ Pressure outlet } & Gauge pressure $(\mathrm{Pa})$ & 0 \\
\cline { 2 - 3 } & Turbulence viscosity ratio & 100.0 \\
\cline { 2 - 3 } & Turbulence intensity & 0.03 \\
\hline Ground & Shear stress specification & Slip condition \\
\hline Front and rear wheel & Angular velocity (rad/s) & 793.65 \\
\hline
\end{tabular}

The air properties were selected based on the following assumptions; room temperature of $23{ }^{\circ} \mathrm{C}$, at an absolute pressure of $1 \mathrm{~atm}$. For the ground region, it is set as a slip condition so that the software is able to simulate the case as being real and where the car is seen as moving along the surface of the ground. Further, the wheels of the car are simulated as if they are actually rotating at a specific angular velocity. All properties from Table 1 and Table 2 remain the same for all car model designs in the simulation. After all the settings have been finalised, the plot on drag and lift coeffi- cient next need to be created so that the results can be analysed for further analysis.

\section{Results and Discussion}

The graphs for drag coefficient against the car model designs are plotted as shown in Figure 6 and Figure 7. From the result of Figure 6 , the value for the drag coefficient decreased from 0.164 to 0.121 from car model design 1 until car model design 5. Also, there is a decrement of around $26.22 \%$. The value of the drag coefficient for car model design 5 and the base design car shows an increment of about $162.54 \%$. Therefore, based on this result, there are two main factors that contribute to the increment of the drag coefficient. These include the flow separation zone at the rear part of the car model and the design of the side pot itself that enables the air flow to become smoother under and at the upper part of the model's body. Also, when the design of the side pot makes the air flow to become smoother, there will be less resistance of air across the car's body which will decrease the drag coefficient of the model. According to Equation (1), when the drag force is increased, the drag coefficient will also increase.

0.2

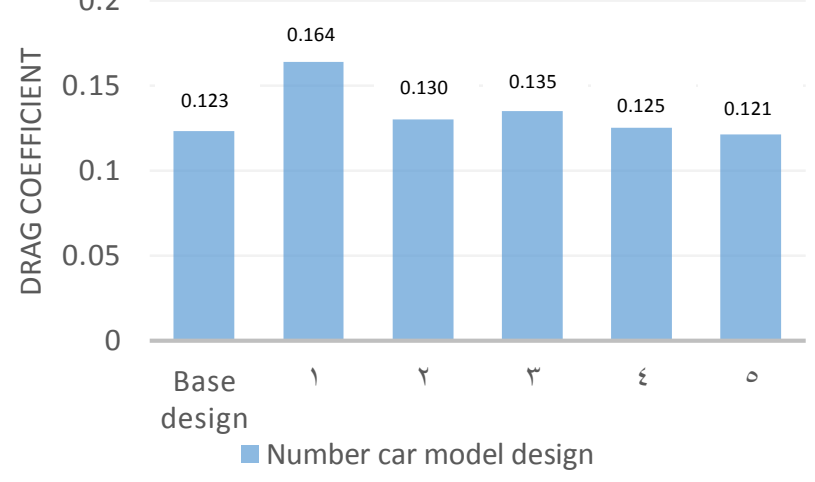

Fig. 6: Graph of the drag coefficient against $\mathrm{n}^{\text {th }}$ car model design.

From Figure 7, the downforce coefficient decreases from car model design 1 to car model design 2 . The value decreases from -0.053 to -0.022 . The contour colour of the air flow on top of the car is almost similar to the bottom of the car. Indeed, there is little difference in the speed of the air flow that occurs between the two parts. The velocity of the air flow at the bottom of the car is slightly higher than at the top of the car which reduces the downforce coefficient as compared with car model design 1 . The reduction of the downforce coefficient is due to the design of the side pot that reduces the air flow speed at the bottom of the car. This in turn, slightly decreased the downforce coefficient between the upper part of the car and under the car due to the small difference in pressure.

The downforce coefficient increases from car model design 2 until car model design 4 from -0.022 to -0.033 . The value increases due to the modification carried out on the model which modified the under-tray part and the side pot of the car. The modification made to the inside of the car side pot caused the air flow under the car to become much smoother. However, due to the difference of the air flow velocity at the upper part of the car and under the car, the downforce increased for car model design 4 when compared with car model design 2 and car model design 3 . The second factor that caused an increase in the downforce was due to the modifications that were made to the under-tray of the car's body. For the design of the under-tray of the car, the thickness of the body for the front part increases as it moves up to the centre part of the car body and decreases moving towards the back of the car. This condition causes the air flow to accelerate and indirectly reduces the pressure under the car. As a result, the downforce will be increased for car model design 4 compared with car model designs 2 and 3 . 


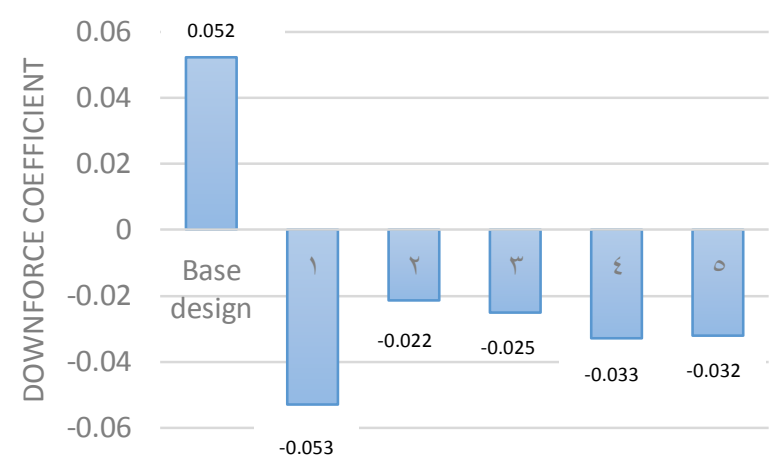

$\square$ Number car model design

Fig. 7: Graph of the downforce coefficient against $\mathrm{n}^{\text {th }}$ car model design.

The flow separation zone will also affect the drag coefficient of the car model. As shown in Figure 8, the flow separation zone for car model 5 is less intense and smaller compared to car model design 4 and the base car design.
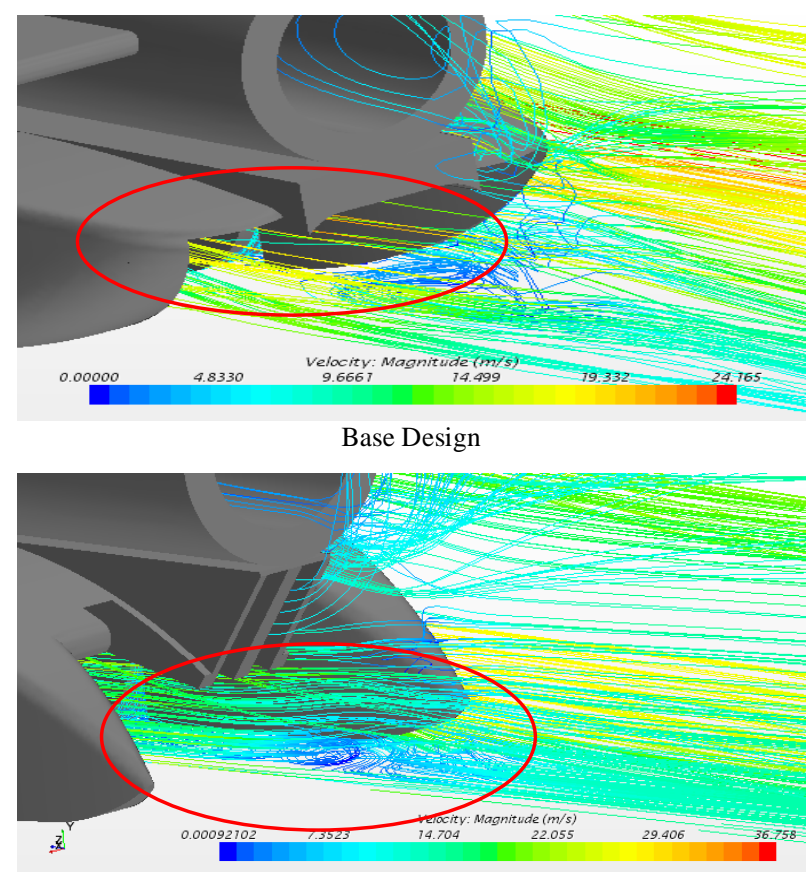

Car Model Design 4

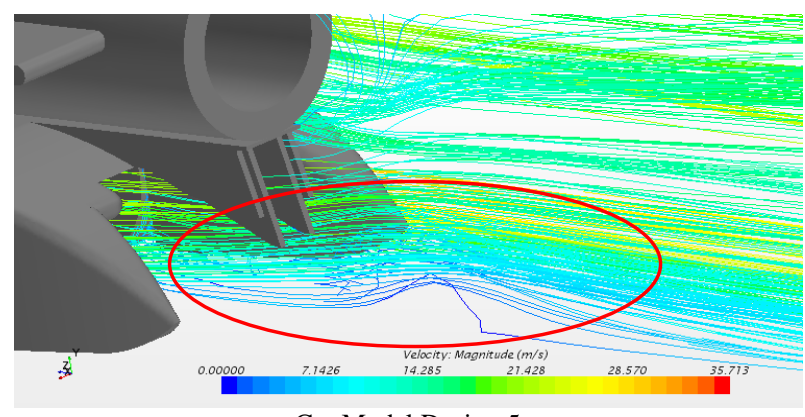

Car Model Design 5

Fig. 8: Flow separation zone.

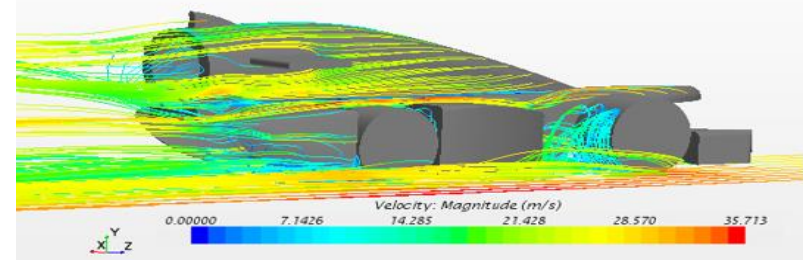

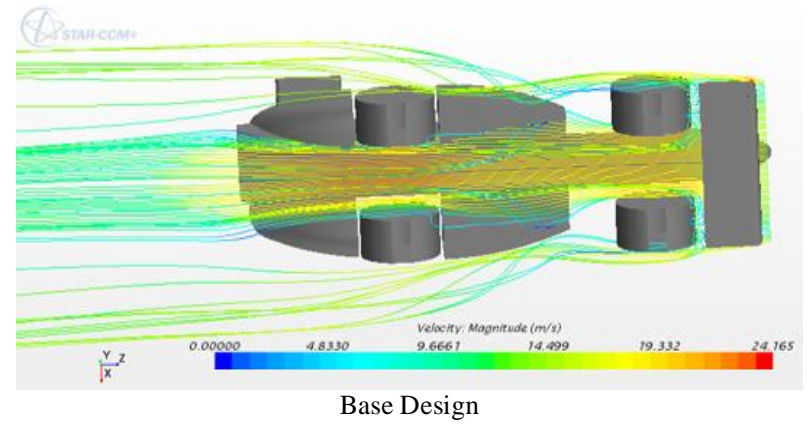
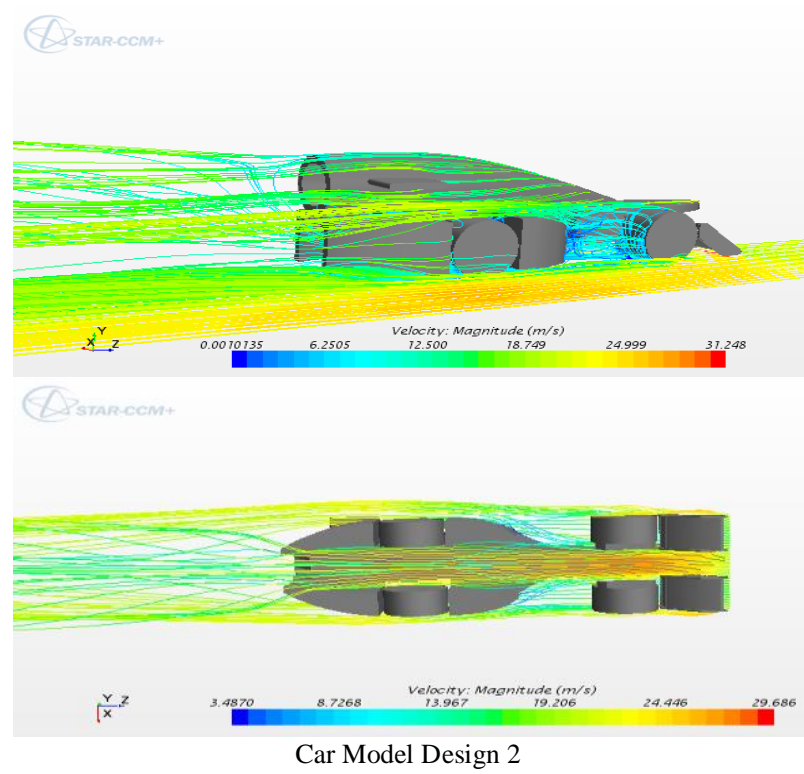

$A \operatorname{srancent}$
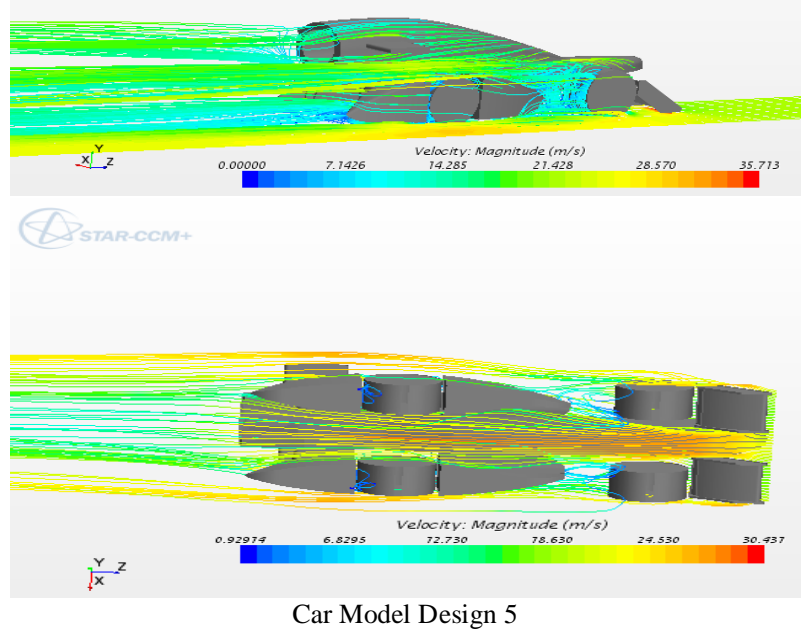

Fig. 9: Differences of the velocity streamline at the upper and under part of the car.

Accordingly, this is due to the modification of the diffuser design and slicing of the car body from $5^{\circ}$ to $13.5^{\circ}$, which successfully decreased the drag force by directing more air flow under the body of the car to the low-pressure zone at the rear part of the car model. Due to the decrement of the size of the flow separation zone, this will also result in a decrease in the pressure difference between the front and rear parts of the car. Thus, the body will have less drag force acting upon it.

From Figure 9, it is shown that there is a slight decrease in the value of the downforce coefficient from -0.033 to -0.032 for car model design 4 and car model design 5 . This decrement is due to 
the increased air flow that occurs at the upper body of the car for car model design 5 compared with car model design 4 . While for the car model base design, the streamline flow of air can be seen for the upper part of the car which has a higher velocity compared to the air flow under the car. Accordingly, this situation will lead to pressure under the car being higher than the upper part of the car, thereby generating lift. The situation was different for car model design 5, where the air flow at the upper part of the car had less velocity than the flow of air under the car. As a result, the downforce coefficient for car model design 5 has a higher value compared with the car model base design which generated lift force instead of downforce affecting the stability of the car during operation.

\section{Conclusion}

The results obtained from performing the STAR CCM + simulation indicates that car model design 5 achieves two important criteria for the aerodynamics of the F1 IN SCHOOLS car. These included; a low drag coefficient of 0.121 and a sufficient amount of downforce coefficient which was -0.032. Applying Equation 1 and Equation 2, the drag and downforce generated by the car was $0.1907 \mathrm{~N}$ and $0.0446 \mathrm{~N}$.

For the drag force, the diffuser design modifications and the modifications at the bottom rear of the car reduced the air flow separation zone behind the car at high speed. The modifications included slicing the underbody of the rear car with an angle of $13.5^{\circ}$. Further, the modification of the diffuser and slicing at the back of the car served to direct the flow of air at the bottom of the car to the rear of the car for the purpose of reducing the impact of the air flow separation zone at the rear of the car.

Finally, the modification of the diffuser, slicing at the bottom rear part of the car body as well as the design side pot and the undertray of the car body was found to effectively solve the problem of reducing drag and increasing downforce.

\section{Acknowledgements}

This work was supported by the Ministry of Science, Technology and Innovation Malaysia [Grant number 06-01-02-SF1326]

\section{References}

[1] Warren FS, Myers M, \& Dansie B (2012), F1 IN SCHOOLS - AN AUSTRALIAN PERSPECTIVE, Proceedings of the ASME 2012 International Mechanical Engineering Congress \& Exposition.

[2] Hetawal S, Gophane M, Ajay BK. \& Mukkamala Y (2014), Aerodynamics study of Formula SAE Car. Procedia Engineering, 97, pp. 1198-1207.

[3] Saad MSS (2013), Study of F1 Car aerodynamics front wing using Computational Fluid Dynamics. Faculty of Mechanical Engineering, Universiti Malaysia Pahang

[4] Rakibul H, Islam SM, Ali TM. \& Islam MQ (2014), Numerical study on aerodynamic drag reduction of racing cars. Procedia Engineering 90 , pp. 308-313.

[5] Cengel YA. \& Cimbala JM (2013), Fluid Mechanics: Fundamentals and Applications, 3rd Edition, McGraw-Hill.

[6] Reddy JJ. \& Mech BT (2006), Finding the Optimum Angle of Attack for the Front Wing of an F1 Car Using CFD, Proceedings of the 4th WSEAS International Conference on Fluid Mechanics and Aerodynamics, pp. 29-34

[7] Pakkam SS (2011), High Downforce Aerodynamics for Motorsport Aerospace Engineering.

[8] Wright P (2001), Formula 1 Technology. Warrendale, PA: Society of Automotive Engineers.
[9] Cooper KR, Bertenyi T, Dutil G, Syms J \& Sovran G. (1998), The Aerodynamic Performance of Automotive Underbody Diffusers. SAE International 724

[10]Sapuan SM, Ham KW, Ng KM, Woo CK., Ariffin MKA, Baharudin B \& Faieza AA (2009), Design of composite racing car body for student-based competition. Scientific Research and Essays 4(11), pp. 1151-1162.

[11]Katz J (2006), Aerodynamics of Race Cars. Annual Review of Fluid Mechanics, 38(1), pp. 1275-1287.

[12]Lim SJ \& Mansor MRA (2017), Aerodynamic Analysis of F1 IN SCHOOL $^{\mathrm{TM}}$ Car. Journal of the Society of Automotive Engineers Malaysia 1(1), pp.41-54. 